\title{
Una nota biográfica sobre Jerónimo de Cáncer y Velasco
}

\author{
A Biographical Note on \\ Jerónimo de Cáncer y Velasco
}

\author{
Elena Martínez Carro \\ Universidad Internacional de La Rioja \\ Alejandro Rubio San Román \\ Universidad Complutense de Madrid
}

\section{RESUMEN}

La fecha y lugar de nacimiento del dramaturgo Jerónimo de Cáncer han sido cuestionados en numerosas ocasiones. Distintos investigadores intentaron localizar - de manera infructuosala documentación sobre el origen del poeta, lo que ha impedido fijar una datación correcta hasta el momento. El presente artículo trata de aportar algunas noticias familiares, especialmente referidas al traslado de Fadrique Cáncer y su mujer a América, para deducir una controvertida hipótesis sobre el nacimiento del poeta.

Palabras Clave: Jerónimo de Cáncer; fecha de nacimiento; lugar de nacimiento; Fadrique Cáncer; documentos; viaje; América.

\section{ABSTRACT}

The place and the date of the Jerónimo de Cáncer's birth have been questioned several times. This article tries to resolve some familiar data, specially those which are related to the emigration of the dramatist's father Fadrique Cáncer and his wife, from Spain to isla Margarita. These facts can help us to deduce the data about the poet Jerónimo's birth.

Key words: Jerónimo de Cáncer; date of birth; place of birth; Fadrique Cáncer; documents; journey; isla Margarita.

En las últimas décadas la crítica viene prestando una especial atención al poeta y dramaturgo Jerónimo de Cáncer y Velasco, y especialmente a su obra poética, como lo demuestran las ediciones de Rus Solera López (Cáncer y Velasco, 2005) y Juan Carlos González Maya (Cáncer y Velasco, 2007) ${ }^{1}$.

\footnotetext{
${ }^{1}$ Entre otros estudios del autor sobre Cáncer y ediciones de sus piezas dramáticas, hay que mencionar el entremés del Francés y las Jácaras a lo divino, de indudable interés por sus aportaciones. Cfr. González Maya (2007: 295-316; 2009: 235-256; y 2012:141).
} 
En los estudios y publicaciones sobre distintos aspectos de sus escritos, surgen -inexorablemente- los problemas en torno a los datos biográficos, imprecisos y desconocidos, como sucede con algunos de sus contemporáneos, pues no existen —en muchos casos - documentos que avalen la tradición literaria. Es necesario solventar estas cuestiones con la aportación de nuevos testimonios, que surgen gracias a las recientes catalogaciones de legajos en los archivos españoles. Con este fin, en anteriores artículos, hemos intentado esclarecer aspectos biográficos de Jerónimo de Cáncer, pero todavía son muchas las incógnitas que existen sobre la vida del poeta (Martínez Carro y Rubio San Román, 2007: 15-32; 2009: 61-77; Rubio San Román y Martínez Carro, 2007: 461-473).

Uno de los aspectos — todavía no documentado- es el lugar y la fecha del nacimiento del que en su tiempo fue considerado un poeta sobresaliente por sus coplas, vejamen y obras dramáticas.

La hipótesis, más aceptada por la crítica, afirma que Jerónimo de Cáncer nació en el año 1599 o a finales del siglo XVI y era natural de Barbastro. Así lo han mantenido Latassa (1798-1802, III: 224), La Barrera², Cotarelo y Mori ${ }^{3}$, Cejador ${ }^{4}$, Hurtado y González Palencia (1940: 700), Sainz de Robles ${ }^{5}$, Urzáiz (2002: 214), Mata Induráin (2003: 1069).

Rus Solera López sintetizó, en una relación exhaustiva y enumerada, las fuentes escritas donde figuraban los datos conocidos sobre el lugar y año de nacimiento de nuestro dramaturgo ${ }^{6}$. Además, efectuó «indagaciones en el Archivo Diocesano de Barbastro para localizar la partida de bautismo de Jerónimo de Cáncer» (Cáncer y Velasco, 2005: XV), pero no logró el éxito esperado, por lo que mantuvo los datos tradicionales que se vienen admitiendo desde Latassa y Ortín, quien especificaba: «nació en la ciudad de Barbastro (Huesca), probablemente a finales del siglo XVI».

Recientemente, González Maya manifestaba la misma incertidumbre en su intento por investigar y esclarecer los orígenes de Jerónimo de Cáncer:

\footnotetext{
${ }^{2}$ «Nació a finales del siglo XVI, en la ciudad de Barbastro; cercano pariente del célebre jurisconsulto don Jaime de Cáncer» (Barrera, 1860: 62).

${ }^{3}$ Cotarelo remite a «don Félix de Latassa que le incluye entre los escritores aragoneses, y le supone nacido en Barbastro, donde también registra el nacimiento de los jurisconsultos Jaime Cáncer que vivía después de 1585 y un hijo suyo que imprimió una obra jurídica en 1618. Serían acaso parientes de don Jerónimo, que vino al mundo en los últimos años del siglo XVI» (Cotarelo y Mori, 1911: LXXXIV).

${ }^{4}$ «Nació en Barbastro de noble familia, sirvió al Conde de Luna como contador, vivió pobre y estrechamente, casose y tuvo una hija de genio tan chistoso como el de su padre» (Cejador y Frauca, 1916: 119). Estas afirmaciones de Cejador las completan y adecuan la crítica posterior.

5 «Nacido en Barbastro muy a finales del siglo XVI» (Sainz de Robles, 1942: 821).

${ }^{6}$ Rus Solera enumeró y señaló las discrepancias entre todos los estudiosos sobre la fecha de nacimiento y recoge las numerosas hipótesis que se han dado: 1582, 1590, 1599, 1600, 1618 (Cáncer y Velasco, 2005: XV).
} 
Sobre la fecha de nacimiento existe una enorme controversia porque no se ha podido dar con ella. Hemos consultado en el Archivo Diocesano de la Catedral de Barbastro los índices y los libros de bautismo y confirmaciones de todos los vecinos desde 1560 hasta 1615, época en que no se registró ningún Jerónimo en los libros [...] de bautismo y [...] confirmación. Ni su partida de desposorios, ni de defunción, ni cualquier otro protocolo consultado nos llevan hacia Barbastro, salvo el origen de su apellido. Dado que Cáncer vivió en Madrid, al menos desde 1624 , buscamos en diferentes parroquias madrileñas en las que se conservan archivos de esta época [...] con resultados igualmente infructuosos (González Maya, 2007: 295-316; y 2012: 141).

Nosotros, al igual que nuestros predecesores, seguimos el mismo camino ${ }^{7}$, pues existían documentos notariales que confirmaban el origen aragonés de la familia. La referencia explícita figura en el segundo testamento de Antonia Cáncer, hija del poeta, quien declaraba así la procedencia de su padre:

Sepan cuantos esta pública escritura de testamento, última y postrimera voluntad, como yo doña María de Cáncer, vecina de esta Villa, [Madrid], hija legítima y de legítimo matrimonio de don Jerónimo de Cáncer, natural del Reino de Aragón y vecino que fue de esta villa, y de doña María Ormaza, natural de esta Corte, difuntos, $[\ldots]^{8}$.

Como sucedió en las indagaciones anteriores no hubo éxito, y si bien es cierto que podríamos dar por perdida la partida de bautismo de Jerónimo de Cáncer, y por tanto la fecha y el lugar de nacimiento, nuestras investigaciones intentaron buscar otras perspectivas y sentido a la expresión «natural de». En los siglos XVI y XVII, esta locución no determinaba, en modo alguno, la localización exacta del nacimiento, sino la ascendencia familiar en el término mencionado. Así, La Barrera —entendiendo el contexto- señalaba que «fue de noble familia; cercano pariente del célebre jurisconsulto don Jaime de Cáncer» ${ }^{9}$. Personalidad que figura entre las más notables de la época en la co-

\footnotetext{
${ }^{7}$ En el Archivo Diocesano de Barbastro, conservado después de la Guerra Civil, se consiguieron salvar los libros de partidas de bautismo, defunción y matrimonios desde 1548. En ellos no se encuentra ningún documento referido a Jerónimo de Cáncer, aunque indudablemente hay muchos vestigios familiares. De hecho entre los años 1601 y 1603, figuran —en dos ocasiones - los nombres de «Jerónima de Cáncer», que por error bien pudieran ser la referencia a nuestro dramaturgo. Sin embargo, los progenitores de las dos niñas no coinciden en absoluto con los nombres de los padres de Jerónimo de Cáncer.

${ }^{8}$ Archivo de Protocolos de Madrid, Protocolo 13.087, fols. 25r-27v (Martínez Carro y Rubio San Román, 2009: 72).

${ }^{9}$ Este parentesco ya lo mencionaba Cayetano A. de La Barrera (Barrera, 1860: 62), pero hay que señalar muy especialmente el estudio de Nicolás S. de Otto (1943: 53-54). En esta semblanza destaca la obra jurídica Variarum resolutionum.

A pesar de las referencias de Zamora Vicente (1953: 143) y de La Barrera (Barrera, 1860: 62), la primera noticia parece ser de Latassa:

Cáncer (Micer Jaime). Descendiente de la noble familia de este apellido, señora que fue del lugar de Cáncer y del Castillo de Ador, cuya salva de infanzonía renovaron en Zaragoza en 1547 los ilustrísimos aragoneses D. Guillermo de Castro,
} 
marca de Barbastro, donde residía la mayor parte del linaje. Las noticias de este familiar son numerosas, pues su fama debió de ser amplia, a juzgar por la obra jurídica que ha llegado hasta nuestros días. Su colaboración en las cortes de Monzón de 1548, junto a sus dos hermanos, marcó a los descendientes de la familia Cáncer como de noble abolengo.

Posiblemente fue el origen familiar lo que llevó a La Barrera, entre otros, a determinar el nacimiento de Jerónimo de Cáncer «en la ciudad de Barbastro» (La Barrera, 1860: 62) como referencia a la «naturaleza» del dramaturgo.

De hecho, otros críticos como Cotarelo y Mori trataron esta cuestión:

Don Félix Latassa (1798-1802, III: 224) le incluye entre los escritores aragoneses, y le supone nacido en Barbastro, donde también registra el nacimiento de los jurisconsultos Jaime Cáncer, que vivía después de 1585, y un hijo suyo que imprimió una obra jurídica en 1618 (Cáncer, 1670). ¿Serían acaso parientes de D. Jerónimo, que vino al mundo en los últimos años del siglo XVI? Pero ni él, ni Nicolás Antonio dan noticias de interés sobre el entremesista, limitándose Latassa a decir que fue familiar del conde de Luna, y Nicolás Antonio celebra en general su ingenio para la poesía jocosa (Cotarelo y Mori, 1911: LXXXIV).

También Marañón planteó un problema similar al hablar de otros personajes como el Conde-Duque de Olivares, aludiendo a la ascendencia territorial y

Vizconde de Ebol, y D. Matías de Moncayo. Fue natural de Barbastro y estudió la Jurisprudencia en las Universidades de Huesca y Salamanca, siendo muy aventajado en esta ciencia. Recibió el bonete de Doctor y fijó su residencia en Barcelona, donde ejerció la Abogacía con notable celo y dignidad, y fue el más célebre Jurisperito de su tiempo en Cataluña, si se exceptúa Fontanella, según don Juan Lucas Cortés; bien que D. Raimundo Rubí de Marimón, Oidor de Barcelona, en el elogio sepulcral que le hizo y se estampó con sus obras, suprime la referida excepción y da a su mérito, sabiduría e integridad de costumbre, un hohor excelente. También intervino con sus tres hermanos en las Cortes de Monzón del año 1585. Murió a los 72 de su edad; habiendo escrito:

$1^{\circ}$ - Variarum Resolutionum Juris Casarei, Pontifitii; et Municipalis Principatus Catalonia. Pars prima, secunda, et tertia, Barcelona, 1594, en tres tomos en folio, que se reimprimieron en dicha ciudad en 1608.

$2^{\circ}$ - Esta misma obra, ab ipso Auctore, antequam é Vita migraret diligentisime recognita, et altero fere tanto aucta, cura, et desiderio D. D. Myr, Regice Audientice Doctoris eximii, Auctoris Generi, in lucem emissa. Pars I, et II. En Turnon de Francia, por Lorenzo Durando, 1635, y parte en Lyon por Lorenzo Arnaud, 1644 y 1659 , y otra vez en 1760 , en tres tomos en folio.

$3^{\circ}$ - Resolutionum, sive Consiliorum istorum, un tomo que desapareció. Después de la muerte de su autor se buscó con diligencia, pero no se halló.

$4^{\circ}$ - Otros discursos y tratados jurídicos, publicados en diversos tiempos.

$5^{\circ}$ - Poesías diversas, con otros papeles estimables.

D. Jaime Cáncer, hijo del autor, llamado el Joven, Doctor en Derechos e ilustre ciudadano de Barcelona, también publicó: Juris Responsum in causa propia supra sua insaculatione in bursa Auditorum Militarium Domus Deputationis. Barcelona, por Lorenzo Deu, 1618, en folio, con otros escritos (Latassa, 1798-1802, III: 224). 
no al lugar de nacimiento ${ }^{10}$. Pero estas indagaciones en torno a los orígenes familiares no son suficientes para esclarecer las incógnitas que nos ocupan. De ahí que la investigación nos haya llevado a indagar en la figura paterna de Jerónimo de Cáncer, hombre de mundo y de relevancia política en su época.

Son numerosos los documentos que se encuentran en los archivos sobre la vida de Fadrique Cáncer y —algunos de ellos — significativos para el tema que nos ocupa.

Gracias a Ángela González-Palencia ${ }^{11}$ sabemos que Fadrique Cáncer vivió en Madrid, en la calle Mayor, antes de que la Villa se extendiera hacia el actual barrio de las Letras, y en la que posteriormente vivirá su hijo, ya huérfano de padre, con su madre. Después de su boda con María Hormaza ocupará una casa en la calle Huertas, frente a la Parroquia de San Sebastián.

Al parecer la estancia en Madrid duró pocos años, pues — como atestigua otro documento de indudable interés de la Real Biblioteca de Palacio- pronto emigró a América como Gobernador de la Isla Margarita. Esta isla tuvo fama, especialmente, por las perlas de sus costas, así como por su situación estratégica. La descripción que el regente lleva a cabo de la salina de Araya ${ }^{12}$, de-

\footnotetext{
${ }^{10}$ Sería un caso semejante al de don Enrique, padre del Conde-Duque de Olivares, cuando señala y recoge Marañón la siguiente salvedad: «nació don Enrique el $1^{\circ}$ de marzo de 1540 , en Madrid, aunque tiene su naturaleza en Sevilla, y en ella y en la Corte pasó todos los años de su niñez y mocedad» (Marañón, 1976: 510).

${ }^{11}$ Señalaba Ángela González- Palencia:

En una escritura de venta de una casa en la calle Mayor que pertenece a D. Fermín Buenaventura Folch, a favor de S. M. Don Fernando VI, y en su nombre a D. Pedro Simó, juez administrador de la renta de Correos y Postas, para establecer en ella y en otras lindantes un hermoso edificio de Correos.- 16 de octubre de 1750 (Diego Trigueros y Dueñas, núm. 17562, fol. 1. Copia de Francisco González del Mazo). Dentro de esta escritura nos interesa la referencia que se hace a los intereses de Fadrique de Cáncer sobre esta casa, así el catorce de junio de seiscientos uno, ante Alonso Carmona, escribano de número, escribe un censo de trescientos ducados a favor del Capitán Fadrique Cáncer. También en la misma escritura se hace referencia ante Gabriel de Rojas, escribano de número, y a la escritura de compra y venta de siete de abril de mil seiscientos quince (González-Palencia, 1953: 368-369).

${ }^{12}$ Véase: «II/175 [Papeles varios de Indias] s. XVI-XVII. [1] h.+578 f. [i.e. 540]: papel; $317215 \mathrm{~mm}$. Autógrafos de Juan de Vega (fol. 10r-12v), Fr. Sebastián de S. Pedro, O.S.A. (fol. 171r-176v), Luis Pérez de las Mariñas (fol. 265r-266v). ... 44.- fol. 220r: Parecer de Fadrique de Cáncer sobre cegar la salina de Araya, 8 de diciembre de 1603 [alt. m.]: Fadrique de Cáncer» (López Vidriero, 1994: 63-65).

Anteriormente, esta información la recogió Domínguez Bordona. En su obra se encuentra el $\mathrm{n}^{\circ}$ 251, Papeles varios, $\mathrm{n}^{\circ}$ 23, «Parecer de Fradique Cáncer sobre cegar la salina de Araya» (fol.115) y en el $n^{\circ} 53$ «Relación de la Salina de Araya por Fradique Cáncer. Año 1603. Original y firmada» (fol. 217) (Domínguez Bordona, 1935: 28-32).

Existe en este documento una doble paginación, por lo que pueden observarse dos foliaciones diferentes en las referencias bibliográficas de los distintos catálogos, pero que responden al mismo manuscrito.
} 
muestra un gran conocimiento de la zona, en la que debió permanecer bastantes años, así como una relación directa con la comarca. Desconocemos — hasta el momento - si llegó a ser propietario o no de la salina, pero lo que sí sabemos con exactitud, es que este contacto con las Américas y servicio a la corona, le supuso «doscientos ducados de renta anual que tiene por merced de S. M., durante la vida, situados en penas de Cámara del Consejo de Indias» ${ }^{13}$. Rentas que cobró Jerónimo de Cáncer a lo largo de su vida, en calidad de herencia, y que dejó posteriormente a su hija Antonia.

El cargo de Gobernador necesariamente debía haber sido registrado en el Archivo General de Indias, donde se anotaban todos los pasajeros, viajes y permisos de la Corte para ejercer oficios importantes en América. Y es aquí donde se conservan algunos documentos reveladores y relacionados con el nacimiento del poeta y el de sus hermanos ${ }^{14}$.

En el censo de viajeros a Indias, figura un legajo datado en 1602, en el que se autoriza a Fadrique Cáncer y a doña Mariana Arce y Velasco, su mujer, para embarcar hacia América:

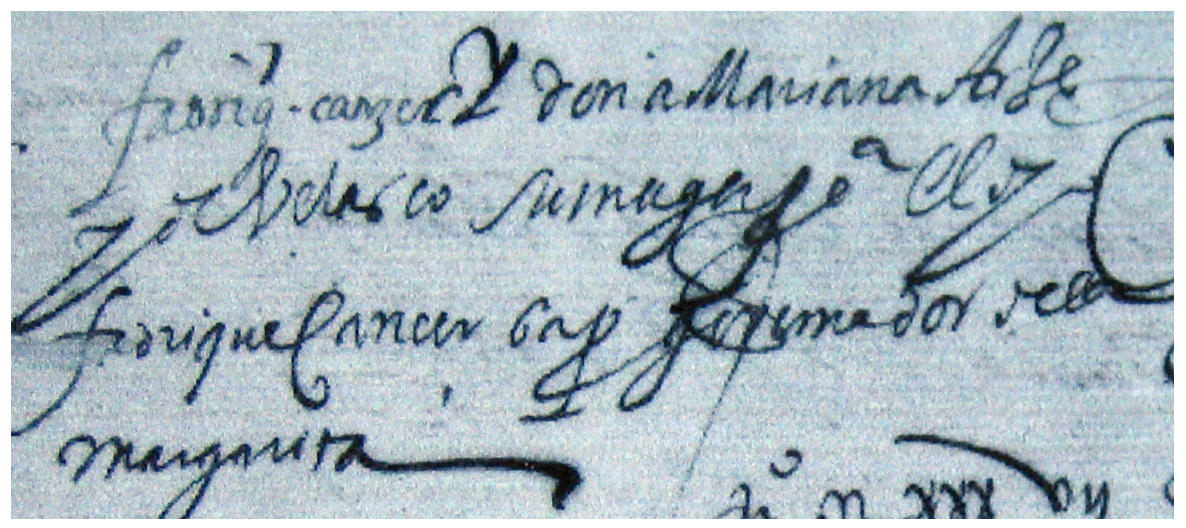

[Fol. 1r] «Fadrique Cáncer y doña Mariana Arce y Velasco, su mujer. El Dicho Fadrique Cáncer, Capitán Gobernador de la isla Margarita».

Fadrique Cáncer, Gobernador por su Majestad de la isla Margarita, digo que - como consta por esta real cédula que presento de su Majestad- me da licencia para que pueda pasar a la dicha isla sin pedir[me] información alguna y que pueda llevar a mi servicio diez criados dándoles en forma conforme a las ordenanzas de esta casa. Por otra real cédula, me da licencia para que pueda llevar en mi compañía a mi mujer, la cual pueda llevar un escudero, cuatro criadas, la una

${ }^{13}$ Testamento de María de Ormaza (viuda de Jerónimo de Cáncer), Archivo de Protocolos, Legajo 8590, fol. 335r-335v (Martínez Carro y Rubio San Román, 2007: 29).

${ }^{14}$ Agradecemos al personal del Archivo General de Indias la ayuda que - con enorme diligencia - nos ha prestado para llevar a cabo este trabajo. 
de ellas casada, y que esta pueda de pasar su marido y sus hijos a la dicha mi mujer, sin pedir información y dándolas las demás personas en forma y por otra real cédula. Así mismo, me da la licencia que el mismo de los diez criados pueda llevar uno de ellos casado, y que este pueda llevar su mujer e hijos.

Por tanto, V.S. pido que - si puedo- me hagan por presentado, y mande ver las dichas cédulas reales, y en su cumplimiento mande se me dé [fol.1v] a mí, a la dicha mi mujer, criados y criadas, el despacho y licencia en la forma acostumbrada, y pido justicia y para ello lo firmo.

Otrasí, digo que la dicha mi mujer está indispuesta, por lo cual no puede parecer personalmente ante V.S., a quien suplico se sirva de mandar, con este, al escribano de esta casa le coteje las señas en su casa a ella y a las criadas de su mujer sobre que pedía justicia.

Fadrique Cáncer ${ }^{15}$.

Como puede observarse, en ningún momento se menciona que el matrimonio tuviera todavía ningún hijo, pues de ser así se hubiese especificado, al igual que en el caso de la criada casada. Por otro lado, la relación de los pasajeros era tan detallada que — en muchos casos- se pedía una reseña a personas externas a la familia. En este caso se recurre al personal de servicio para conseguir la descripción de los rasgos de la mujer del Capitán Fadrique ${ }^{16}$.

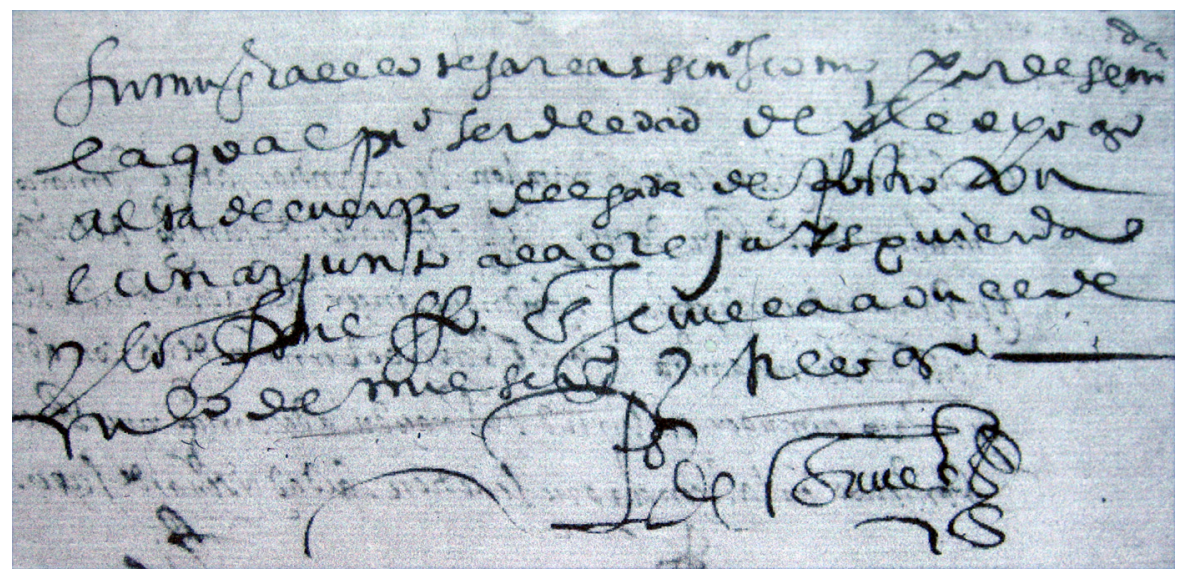

[Fol. 3r] «Su mujer deja ver las señas como y de semejanza, la cual prometió ser de edad de veinte algo años. Alta de cuerpo, delgada de rostro, con un lunar junto a la oreja izquierda y lo pone y semeja a cerulo de menjuí $[\ldots] »^{17}$.

${ }^{15}$ Archivo General de Indias, Contratación, 5275, n. 63, fol. 1r-1v.

${ }^{16}$ En el Archivo General de Indias se pueden ver las «contrataciones» al personal de servicio que el matrimonio llevó en el viaje de 1603. Los nombres de los criados que fueron a América son: Andrés García Villarín, Baltasar de Escobedo, Beatriz de los Reyes, Catalina Cano, Diego de Castro, Diego de León, Diego Pérez, Francisca Carrillo, Jerónimo Hernández, Pedro de Arcos y Tomás Jiménez.

${ }^{17}$ Archivo General de Indias, Contratación, 5275, n. 63, fol. 3r. 
Posiblemente, no exista un retrato más detallado de la madre de Jerónimo de Cáncer que el que nos aporta el escribano de este documento.

Sin embargo, y a pesar de que toda la documentación estaba en orden, algo debió de suceder en la familia para que el viaje se retrasara. Posiblemente el nacimiento del primer hijo sucedió en medio de los preparativos, pues la mujer del Gobernador se encontraba ya indispuesta en el momento de la declaración. Así el permiso real — dado el veintiséis de junio de 1602- se retrasó al trece de marzo de 1603, fecha en la que por fin partieron a América.

[Fol. 3v] Sevilla, en la Casa de la Contratación de las Indias, a trece de marzo de mil y seiscientos y tres años. Los señores Presidente y Jueces Oficiales de su Majestad de la dicha Casa, dijeron que darán y dieron licencia a Fadrique Cáncer para pasar, y que pase, a la isla Margarita a donde va por Gobernador de ella con doña Mariana de Arce y Velasco su mujer en virtud de una cédula de Majestad que presentó en esta Casa, poniendo en la licencia que se diera la calidad y señas de su persona.

Traslado de una cédula de su Majestad que presentó en esta Casa, Fadrique Cáncer, que va por Gobernador a la isla Margarita.

El Rey

Mis Presidentes, Jueces Oficiales de la Casa de la Gobernación de Sevilla, yo os mando dejéis pasar a la isla Margarita a Fradique Cáncer, a quien he proveído por mi Gobernador de esta, y que pueda llevar seis criados a él, sin pedir información alguna y los demás, presentando las anteriores hechas en sus tierras, ante la justicia de ellas y con aprobación de la misma justicia, de cómo ni casados, ni solteros, hallaran aquella parte y dichas señas de sus personas. En Valladolid, a cinco de febrero de mil y seiscientos y dos años, Yo el Rey. Por mandado del Rey, nuestro señor. Juan de Ybarra y en las espaldas de la dicha estando señales de firmas. El cual dicho traslado ha corregido y contestado con la carta su señal. Sevilla a trece de marzo de mil y seiscientos y tres años ${ }^{18}$.

Poco sabríamos sobre nuestro objetivo, si este fuera el único documento conservado acerca del traslado del matrimonio a la isla Margarita. Pero junto a él se encuentra otro despacho, datado el 23 de febrero de 1612, nueve años después, por el que se autoriza a la familia para acometer un nuevo viaje a Trujillo, provincia de Perú. En este expediente, se señala cuál es la situación de Fadrique Cáncer y su prole, pues figuran —en el encabezamiento- los nombres de los hijos:

[Fol. 1r] Fadrique Cáncer que va por corregidor de la ciudad de Trujillo. Doña Mariana Velasco, su mujer. Juan y Jerónimo. D ${ }^{a}$ Ana, Da Luisa y D ${ }^{a}$ María, sus hijos, solteros por declaración de 13 de julio de $1611^{19}$.

El expediente fechado entre 13 de julio de 1611 y el 23 de febrero de 1612 continúa la descripción de la familia y vuelve a nombrar a cada uno de los vástagos:

[Fol. 3r] Presidente y jueces oficiales de la Casa, dijeron que daban, y dieron licencia, a Fadrique de Cáncer, que va por Corregidor de la ciudad de Trujillo, en

\footnotetext{
${ }^{18}$ Archivo General de Indias, Contratación, 5275, n. 63, fol. 3v.

${ }^{19}$ Archivo General de Indias, Contratación, 5327, n. 17, fol. 1r.
} 
las provincias del Perú, para que puedan pasar y pase a ella, llevando consigo a doña Mariana de Velasco, su mujer. Y que pueda llevar a Juan, Jerónimo, doña Ana, doña Luisa y doña María: sus hijos. Y cuatro criados y dos criadas para ser servido. Déseles licencia en virtud de la cédula de su Majestad, que presenta en esta casa el dicho Fadrique de Cáncer, a los cuales se les ha de poner licencia, que se les diere: la edad y señas de sus personas ${ }^{20}$.

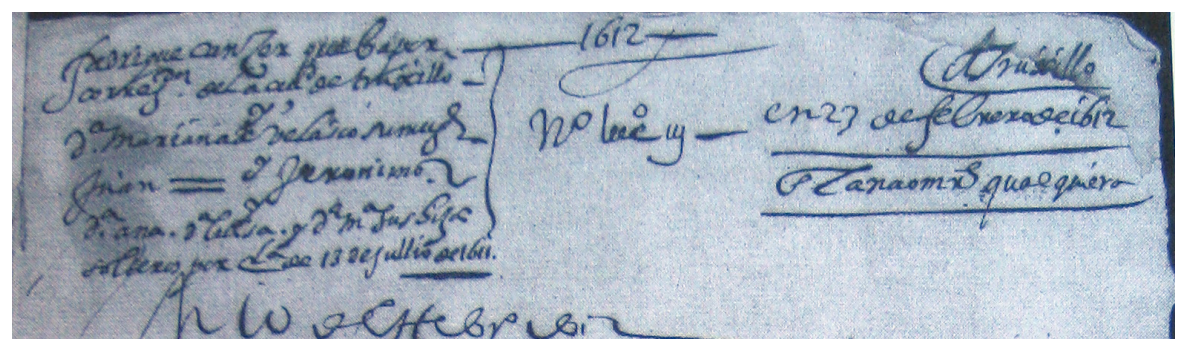

En el mismo legajo existe una copia de la cédula real en la que se concede este traslado:

El Rey: Mis presidente y jueces oficiales de la Casa de la Contratación de la ciudad de Sevilla, yo los mando que al Capitán Fadrique de Cáncer, a quien he proveído, por mí, corregidor de la ciudad de Trujillo de las provincias de Perú: le dejéis pasar a aquellas tierras, llevando consigo su mujer y que pueda llevar a sus hijos, sin le pedir información alguna. Fecha en San Lorenzo, a trece de julio de mil seiscientos once años. Yo, el Rey.

Por mandado del Rey, Nuestro Señor. Pedro de Ledesma, y a las espaldas de la dicha cédula están seis rúbricas de firmas.

El cual dicho traslado fue sacado de la dicha real cédula y corregido con ella, en Sevilla, a diez y ocho de febrero de $1612^{21}$.

Ambos documentos nos llevan a deducir que los hijos del matrimonio Fadrique Cáncer y Mariana Velasco nacieron —en su mayoría- en América, y concretamente en la isla Margarita. Desconocemos que exista otro desplazamiento anterior al de Trujillo, traslados que — como puede verse por las cédulas - eran muy considerados por el Rey. De haberse producido algún otro viaje constaría en los expedientes estudiados. Por tanto, se puede conjeturar - como hipótesis y de acuerdo con estas aportaciones- que Jerónimo de Cáncer nació en América, lo que justificaría la infructuosa búsqueda — que todos hemos seguido- de su partida de bautismo en Barbastro.

Por otro lado, este certificado ${ }^{22}$ revela una anotación marginal de indudable interés. En él figuran las edades de los hijos del matrimonio. Jerónimo de Cáncer es el menor de los descendientes con tan solo cuatro años, por lo que

\footnotetext{
${ }^{20}$ Archivo General de Indias, Contratación, 5327, n. 17, fol. 3r.

${ }^{21}$ Archivo General de Indias, Contratación, 5327, n. 17, fol. 2v.

${ }^{22}$ Archivo General de Indias, Contratación, 5327, n. 17, fol. 2v.
} 
es posible inferir que nuestro dramaturgo nació alrededor de 1608. Indudablemente esta es una fecha controvertida y tardía si se tiene en cuenta la datación de su matrimonio, el 3 de noviembre de 1625 en la Iglesia de San Sebastián de Madrid, pues habría contraído nupcias con tan solo diecisiete años. Sin embargo, creemos que el documento es revelador, pues es el primer testimonio de carácter jurídico donde se señala el único antecedente conocido de la infancia del poeta. La fecha sirve como referencia para una posible datación de su nacimiento, aunque la confrontación con los hechos conocidos de su juventud nos lleve a pensar en un error.

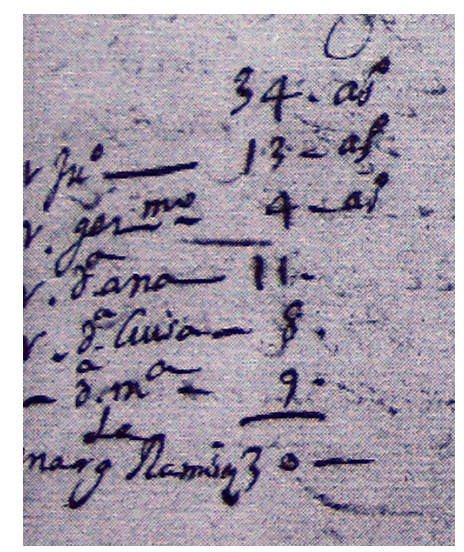

Esperamos, que como sucede con tantos hechos biográficos y velados del poeta, podamos esclarecer — con mayor fortuna - algunos de ellos sobre sus años de juventud, en próximos artículos.

\section{BIBLIOGRAFÍA CITADA}

Barrera, Cayetano A. de la (1860). Catálogo bibliográfico y biográfico del Teatro Antiguo Español desde sus orígenes hasta mediados del siglo XVIII. Madrid: Rivadeneyra.

Cáncer y Velasco, Jerónimo de (2005). Obras varias. Rus Solera (ed.). Zaragoza: Larumbe.

Cáncer y Velasco, Jerónimo de (2007). Poesía completa. Juan Carlos González Maya (ed.). Madrid: Fundación Universitaria Española.

Cáncer, Jaime (1670). Iacobi Cancerii, Domicelli Babastr, I.V.D. Clarissimi, Variarum resolutionum Iuris Caesarei, pontificij \& municipali Principatus Cathalauniae... pars prima [-secunda]. Editio nouissima aucta et a mendis expurgata. Lugduni: sumpt. Laur. Arnaud et Petri Borde.

Cejador y Frauca, Julio (1916). Historia de la lengua y literatura castellana. Madrid: Tip. de la Revista de Archivos, Biblioteca y Museos.

Cotarelo y Mori, Emilio (1911). Colección de entremeses, loas, bailes, jácaras y mojigangas desde finales del siglo XVI a mediados del siglo XVIII. Madrid: Casa Editorial BaillyBailliére. 
Domínguez Bordona, Jesús (1935). Manuscritos de América. Madrid: Talleres de Blass.

González Maya, Juan Carlos (2007). «Entremés del «Francés» de Jerónimo de Cáncer», en Carlota Vicens Pujol (ed.), Au bout du bras du fleuve: miscelanea a la memoria de Gabriel Ma Jordà Lliteras. Palma de Mallorca: Universitat de les Illes Balears, pp. 295316.

González Maya, Juan Carlos (2009). «Jácaras a lo divino: un inédito de Cáncer y Velasco», Revista de Literatura. 141, pp. 235-256.

González Maya, Juan Carlos (2012). «Jerónimo de Cáncer y Velasco», en Pablo Jauralde Pou (dir.), Diccionario Filológico de Literatura Española. S.XVII, I. Madrid: Castalia, pp. 141-170.

González-Palencia Simón, Ángela (1953). Colección de documentos sobre Madrid. Madrid: CSIC.

Hurtado, Juan y Ángel González-Palencia (1940). Historia de la literatura española, Madrid: Ed. Tradicionalista.

Latassa, Félix de (1798-1802). Biblioteca nueva de los escritores aragoneses que florecieron desde el año 1500 hasta 1802. Pamplona: Joaquín Domingo.

López Vidriero, María Luisa (1994). Catálogo de la Real Biblioteca. Manuscritos. Madrid: Patrimonio Nacional.

Mata Induráin, Carlos (2003). «Cáncer y la comedia burlesca», en Javier Huerta Calvo (dir.), Historia del teatro español, I. De la Edad Media a los Siglos de Oro. Abraham Madroñal Durán y Héctor Urzáiz Tortajada (coords.). Madrid: Gredos, pp. 1069-1096.

Marañón, Gregorio (1976). Obras completas. Alfredo Juderías (ed.). Madrid: Espasa-Calpe.

Martínez Carro, Elena y Alejandro Rubio San Román (2007). «Documentos sobre Jerónimo de Cáncer y Velasco», Lectura y Signo. 2, pp. 15-32.

Martínez Carro, Elena y Alejandro Rubio San Román (2009). «Documentos sobre Jerónimo de Cáncer y su familia. Parte II», Lectura y Signo. 4, pp. 61-77.

Otto, Nicolás S. de (1943). Pablo IV y la Corona Española. Micer Jaime de Cáncer. Su obra. Zaragoza: Tip. La Académica.

Rubio San Román, Alejandro y Elena Martínez Carro (2007). «Relaciones entre Rojas Zorrilla y Jerónimo de Cáncer», ARBOR. CLXXXIII, pp. 461-473.

Sainz de Robles, Federico (1942). El teatro español. Historia y antología. (Desde el siglo $X I V$ al XIX). Madrid: Aguilar.

Urzáiz Tortajada, Héctor (2002). Catálogo de autores teatrales del siglo XVII. Madrid: Fundación Universitaria Española.

Zamora Vicente, Alonso (1953). Diccionario de Literatura Española. G. Bleiberg (coord.). Madrid: Revista de Occidente.

Fecha de recepción: 7 de junio de 2013.

Fecha de aceptación: 7 de enero de 2014. 
